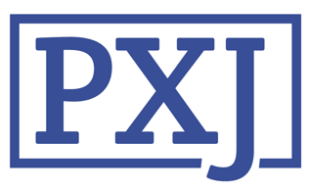

Patient Experience Journal

\title{
Exploratory pilot testing of the psychometric properties of the person engagement index instrument among older, community- dwelling adults
}

\author{
Ellen Swartwout \\ GetWellNetwork \\ Taya Irizarry \\ University of Pittsburgh \\ Annette DeVito Dabbs \\ University of Pittsburgh \\ Scott Barnett \\ James A Haley Veterans Medical Center
}

Follow this and additional works at: https://pxjournal.org/journal

Part of the Health Services Administration Commons, Health Services Research Commons, and the Nursing Administration Commons

\section{Recommended Citation}

Swartwout E, Irizarry T, Dabbs AD, Barnett S. Exploratory pilot testing of the psychometric properties of the person engagement index instrument among older, community-dwelling adults. Patient Experience Journal. 2017; 4(3):86-94. doi: 10.35680/2372-0247.1206.

This Research is brought to you for free and open access by Patient Experience Journal. It has been accepted for inclusion in Patient Experience Journal by an authorized editor of Patient Experience Journal. 


\section{Exploratory pilot testing of the psychometric properties of the person engagement index instrument among older, community-dwelling adults}

\section{Cover Page Footnote}

Acknowledgements The authors would like to acknowledge the consultation of Scott R. Beach PhD, Associate Director and Program Director of Survey Research of the University Center for Social and Urban Research (UCSUR) at the University of Pittsburgh and UCSUR's professionally trained and experienced interviewers who administrated the survey by phone in September of 2015. Funding This study was supported by a grant from the University of Pittsburgh Aging Institute / Health Policy Institute Seed Grant Program. 


\title{
Exploratory pilot testing of the psychometric properties of the person engagement index instrument among older, community-dwelling adults Ellen Swartwout, PhD, RN, NEA-BC, FAAN, O'Neil Center at GetWellNetwork, eswartwout@getwellnetwork.com Taya Irizarry, PhD, RN, University of Pittsburgh, tai19@pitt.edu Annette DeVito Dabbs, PhD, RN, FAAN, University of Pittsburgh, ajdst42@pitt.edu Scott Barnett, PhD, James A Haley Veterans Medical Center, scottdb65@gmail.com
}

\begin{abstract}
The objective of this paper was to evaluate the psychometric properties of the Person Engagement Index with community dwelling older adults and determine the factors that impact this population's capacity to engage in healthcare. This nonexperimental pilot evaluation of the psychometrics of the Person Engagement Index was performed in a convenience sample of 100 community-dwelling older adults. Exploratory factor analysis was conducted using dimension reduction to determine the underlying structure of a person's capacity to engage in healthcare. Results indicated good internal consistency with Cronbach's alpha $=.882$ for the overall scale. Exploratory factor analysis with varimax rotation was conducted resulting in a five-factor solution. Four of the five subscales exceeded Cronbach's alpha $>.70$ threshold for internal consistency. Cronbach's alpha results for the five domains were: (Knowledge of Healthcare Status) =.886, (Proactive Approach to Healthcare) $=.780$, (Motivation to Manage Healthcare) $=.742$, (Psychosocial Support for Healthcare) $=.658$ and (Technology Use in Healthcare) $=.796$. Results suggest that the Person Engagement Index instrument is a valid and reliable instrument to measure a person's capacity to engage in healthcare among community dwelling older adults. Testing in different settings with other populations and over time is warranted to further explore the reliability and validity of the Person Engagement Index for different subgroups and its sensitivity to changes in health status that may impact a person's capacity to engage in care.
\end{abstract}

\section{Keywords \\ Patient-centered, patient engagement, psychometric testing, older adults}

\section{Note}

The authors would like to acknowledge the consultation of Scott R. Beach PhD, Associate Director and Program Director of Survey Research of the University Center for Social and Urban Research (UCSUR) at the University of Pittsburgh and UCSUR's professionally trained and experienced interviewers who administrated the survey by phone in September of 2015. Funding; This study was supported by a grant from the University of Pittsburgh Aging Institute / Health Policy Institute Seed Grant Program.

\section{Background}

Patient-centered care, a key component of healthcare reform, is critical for improving healthcare outcomes. ${ }^{1}$ In order to achieve patient-centered care, it is important to know patients' preferences, wants and needs relevant to their healthcare goals. In addition, effective patientcentered care requires an understanding of the ways in which patients interact with healthcare professionals, healthcare systems and the community. Partnering with patients and their families to be actively engaged in their care is recognized as a significant factor in improving healthcare outcomes. ${ }^{2}$ For example, when patients were involved in their healthcare and quality efforts, outcomes improved. ${ }^{3}$ Furthermore, knowing that mutual healthcare goal setting is a key component in determining informed decision-making among patients, families and clinicians, a study found that an instrument focused on measuring what was most important to patients and identifying next steps in their healthcare journey, were critical for moving towards true care partnerships. 4,5

The most commonly used instrument to measure patient involvement with their healthcare is the Patient Activation Measure (PAM) ${ }^{6}$ In a study that evaluated the influence of one's activation score, key outcomes included a reduction in average length of stay, increased adherence with healthcare regimens, and better relevant lab results for patients with high cholesterol or diabetes. ${ }^{2}$ Although the 13-item PAM measure is indicative of one's involvement in their care, other factors are critical to evaluate a person's capacity to be engaged in that care. 
In order to support the ability of clinicians to practice within a patient-centered model and partner with patients in their care, an instrument to assess a person's capacity to engage in his or her care was an identified need to assist people with engaging in their care journey. As a result, the Person Engagement Index instrument was developed to measure a person's capacity to engage in their healthcare.

The health and healthcare needs of older adults increase in complexity as one ages. Older adults are more likely to have a chronic condition or multiple co-morbidities and be on multiple medications, ${ }^{7}$ requiring even greater engagement on the part of the older adult and the healthcare team. This complexity, coupled with complications associated with the natural aging process (e.g., cognitive decline, changes in eyesight, hearing loss and higher risk of depression) requires an even greater understanding of older adults' capacity to engage with the healthcare professionals who serve them ${ }^{8}$. Thus, older adults were selected as the focus for initial testing of the psychometric properties of the Person Engagement Index to assess their capacity for engagement. Therefore, the purpose of this initial exploratory pilot study was to evaluate the psychometric properties of the Person Engagement Index in a sample of community-dwelling older adults.

\section{Instrument Development}

The conceptual framework for this exploratory pilot study was the Interactive Care Model TM (ICM), a five phase care delivery process model for better engaging people in their care. The assessment phase of the model is the focus for the development of this instrument to measure a person's capacity to engage in their healthcare. ${ }^{9}$ In a comprehensive review of the literature, which explored the following databases: CINAHL Complete, MEDLINE Complete, Mental Measurements, PUBMED and SocINDEX, it was found that in addition to a patient's level of activation, seven other factors that can influence a person's capacity to engage were identified. The eight factors include: 1) patient preferences, values, and needs; 2) activation /motivation; 3) health literacy; 4) disease burden; 5) preventative measures; 6) psychosocial components; 7) technology use in healthcare and; 8) involvement in healthcare safety. 1,2,4,10-14 Several of these factors had measurement instruments focused on the specific domain only and not in a combined scale to measure a person's capacity to engage in their healthcare. , $, 6,13,15-21^{2}$

The combined information from review of the literature and expert consultation was used to develop five items for each of the eight domains to measure a person's capacity to engage in their healthcare. The 40 original items underwent expert review by eight members of a multidisciplinary Clinical Advisory Council. This interprofessional pool of content experts included nursing leaders with expertise in patient engagement in academia, practice, and research, and leaders in patient engagement and education in medicine and pharmacy. Content validation was conducted using item-content validity index (I-CVI) of the original 40 items, on a relevancy scale of one to four where, $1=$ no relevancy, $2=$ somewhat relevant, $3=$ quite relevant and $4=$ highly relevant .22 I-CVI scores of .78 or higher were considered relevant to the capacity to engage in healthcare construct being measured. Eleven of the original 40 items were below the I-CVI threshold and considered for deletion. The items deleted had I-CVI scores of ranging from .625-.75. Based on the scores for item content validation, expert feedback, and the importance of the item to the overall study objectives, the Person Engagement Index was revised to include 24 items (three per domain) to test in this exploratory pilot study.

\section{Methods}

\section{Participants}

Institutional Review Board (IRB) approval was obtained for this study. Participants were obtained from a convenience sample of 100 community-dwelling older participants (65 years of age and older) of an existing IRBapproved research registry maintained by the University Center for Social and Urban Research (UCSUR) who agreed to complete the telephone survey. Participants were recruited from a variety of population-based surveys conducted by UCSUR (Refer to Table 1 for registry characteristics). Table 1 demonstrates UCSUR Registry participants' adequate variation in the social-behavioral characteristics of interest; $39 \%$ of registry participants are at least 65 years of age and 19\% of the older adults display evidence of low health literacy.

\section{Instrument}

The Person Engagement Index uses a 5-point Likert Scale: strongly disagree $=1$; disagree $=2$; neither agree nor disagree $=3$; agree $=4$; and strongly agree $=5$. A higher rating indicates a greater capacity to engage in one's healthcare. Readability of the instrument items included examination of the Flesh-Kincaid Grade level $=7.4$ and the Flesh Reading Ease $=70.4 / 100 .{ }^{22}$ Items were dispersed throughout the survey for each of the domains. Subscales were scored by summing Likert scored items (range: 1-5) within each respective subscale and subsequently normalized using min-max scaling.

\section{Procedures}

Following informed consent, participants were verbally interviewed by phone by a trained survey administrative professional. The instrument is designed to be administered electronically, paper and pencil or verbally over the phone by a trained survey administrative professional. Phone interviews were an average of 15 minutes long. 
Table 1: Characteristics of UCSUR Registry Participants $(n=1000)$

\begin{tabular}{ll} 
Non-white race & $10 \%$ \\
\hline Non-English speaking & $3 \%$ \\
\hline Low education $\leq$ high school & $33 \%$ \\
\hline Low income $\leq \$ 25 \mathrm{~K}$ & $24 \%$ \\
\hline Uninsured & $7 \%$ \\
\hline Poor overall health & $19 \%$ \\
\hline Low health literacy & $19 \%$ \\
\hline & \\
\hline Sub-group $\geq 65$ years $(\mathrm{n}=395)$ & $39 \%$ \\
\hline Require help reading instructions & $13 \%$ \\
\hline Difficulty understanding written & $11 \%$ \\
\hline Difficulty completing forms & $27 \%$
\end{tabular}

\section{Statistical Analysis}

All analyses were performed using SPSS (version 21.0, IBM, Inc., Chicago, IL). Appropriate descriptive statistics (mean, standard deviation, median, range, frequency and percentage) were used to summarize participant characteristics. To investigate interrelationships and possible clustering among items, Pearson correlation coefficients were used. An exploratory factor analysis (EFA) with principal axis factoring (PCA) extraction and orthogonal varimax rotation was used to explore the underlying structure of the scale.

A Kaiser-Meyer-Olkin value of $\geq 0.80$ was used to indicate an adequate sample and a significant Bartlett's test was used to indicate appropriateness of PCA. In the PCA solution, the scree test and total variance explained were examined to determine the number of underlying factors in the Person Engagement Index scale. Factors with eigenvalues greater than 1.0 were extracted. In the extraction phase, items that met a minimum factor loading of .40 were considered relevant. Two items loaded on more than one factor but given factor loading differences of $<.2$, a decision was made to restrict each item to the factor with higher loading. If the items did not load on any factor at the cut-off of $>.40$, the item was flagged for further investigation.

Subscales were interpreted and labeled by the research team based on identified factors using this EFA approach. Lastly, internal consistency of subscales was assessed using Cronbach's alpha coefficient, a reliability index that estimates the internal consistency of the items in the instrument. Alpha coefficients and item-total correlations were examined. An alpha coefficient of .70 or higher was considered to be acceptable.

\section{Results}

\section{Sample Characteristics}

The mean age of the respondents was 75 years old. For sample characteristics of age, gender, marital status, race, educational level, employment status and annual income, please refer to Table 2 .

\section{Item Characteristics}

The overall total scale mean score was 4.14 , indicating a high level of capacity for engaging in one's healthcare among this sample of community-dwelling older adults. Item means ranged from 3.17 to 4.39 . The item with the lowest mean score was: It is a challenge to participate in activities that would improve my health, due to my health problems and the item with the highest mean score was: When something seems "not right" to me in my healthcare, I speak up to my doctor, nurse, care team members or family. The domain subscale mean scores ranged from 3.63 to 4.29. The domain with the highest mean score was Knowledge about Healthcare Status and the lowest mean score was the Technology Use in Healthcare domain. (Refer to Table 3 for item characteristics). During survey administration, none of the older adults surveyed expressed any misunderstanding or requested further explanation of the questions, indicating that the respondents had a good understanding of the questions posed.

\section{Descriptive Statistics Between Factor Correlations and Cronbach's Alpha Coefficients}

Table 4 presents the descriptive statistics between factor correlations and Cronbach's alpha coefficients for the five generated subscales (corresponding to Factors I to V). Internal consistency ranged from .658 to .886. All Person Engagement Index subscales demonstrated good internal consistency. The correlations among the subscales ranged from .272 to .658 (Refer to Table 4 for factor correlations). The item-total correlations were good for all items within the subscales: Knowledge of Healthcare Status (.425 to .627), Proactive Approach to Healthcare (.297 to.652), Motivation to 
Table 2. Sample Characteristics

\begin{tabular}{|c|c|}
\hline Total Sample $=100$ & Frequency, $(\%)$ \\
\hline $\begin{array}{l}\text { Age } \\
\text { 65-74 years } \\
75-84 \text { years } \\
85-97 \text { years }\end{array}$ & $\begin{array}{l}56(56 \%) \\
29(29 \%) \\
15(15 \%)\end{array}$ \\
\hline $\begin{array}{l}\text { Gender } \\
\qquad \begin{array}{l}\text { Female } \\
\text { Male }\end{array} \\
\end{array}$ & $\begin{array}{l}58(58 \%) \\
42(42 \%) \\
\end{array}$ \\
\hline $\begin{array}{l}\text { Marital Status } \\
\text { Single or Divorced } \\
\text { Married or Living with a Partner } \\
\text { Widowed }\end{array}$ & $\begin{array}{l}24(24 \%) \\
48(48 \%) \\
28(28 \%) \\
\end{array}$ \\
\hline $\begin{array}{l}\text { Race } \\
\text { White } \\
\text { African American } \\
\text { Other } \\
\text { Preferred Not to Answer } \\
\end{array}$ & $\begin{array}{c}78(78 \%) \\
15(15 \%) \\
6(6 \%) \\
1(1 \%) \\
\end{array}$ \\
\hline $\begin{array}{l}\text { Formal Education } \\
\text { Less than High School } \\
\text { High School/GED } \\
\text { Vocational/Associates } \\
4 \text { Year College } \\
\text { Graduate/Professional } \\
\text { Preferred Not to Answer } \\
\end{array}$ & $\begin{array}{c}4(4 \%) \\
27(27 \%) \\
29(29 \%) \\
23(23 \%) \\
16(16 \%) \\
1(1 \%) \\
\end{array}$ \\
\hline $\begin{array}{l}\text { Current Employment } \\
\text { Full/Part-time or Looking for work } \\
\text { Retired }\end{array}$ & $\begin{array}{l}16(16 \%) \\
84(84 \%)\end{array}$ \\
\hline $\begin{array}{l}\text { Annual Income } \\
\qquad \begin{array}{l}\text { Unknown } \\
\$ 0-\$ 14,999 \\
\$ 15,000-\$ 39,999 \\
\$ 40,000-\$ 69,999 \\
\$ 70,000-\$ 100,000 \text { or more }\end{array}\end{array}$ & $\begin{array}{c}6(6 \%) \\
16(16 \%) \\
31(31 \%) \\
30(30 \%) \\
17(17 \%)\end{array}$ \\
\hline
\end{tabular}

Manage Healthcare (.220 to.580), Psychosocial Support for Healthcare (.069 to.584) and Technology Use in Healthcare (.490 to .623).

\section{Reliability}

Results indicated good internal consistency for the overall scale with Cronbach's alpha=.882. Four of the five subscales exceeded Cronbach's alpha $>.70$ threshold for internal consistency of the instrument. Cronbach's alpha results for the five domains were: Factor I (Knowledge of Healthcare Status) $=.886$-; Factor II (Proactive Approach to Healthcare) $=.780 ;$ Factor III (Motivation to Manage Healthcare) =.742; Factor IV (Psychosocial Support for Healthcare) =.658; and Factor $V$ (Technology Use in Healthcare $)=.796$. After an examination of total item correlations and Cronbach's alpha change if an item is deleted for the total scale, five item correlations were below the .40 threshold, ranging from .094 to .392 . Three of these items would have increased reliability for the overall scale, if removed from the scale: I rely beavily on others to assist me with my health problems, would increase Cronbach's alpha to .888; It is a challenge to participate in activities that would improve my health, due to my health problems would increase Cronbach's alpha to.886; and I have limited ability to participate in managing my bealth, due to my bealth problems would increase Cronbach's alpha to .883 .

\section{Construct Validity: Factor Loadings}

The initial unrotated principal components analysis included six components extracted with eigenvalues greater than 1.0 and commonalities ranging from .466 to. 783. After examination of the scree plot and percent variance explained by the component, it was determined a five factor solution was supported. The sixth component had an eigenvalue greater than 1; however, it had less than $5 \%$ contribution to the overall percent variance explained (4.5\%), supporting the five-factor solution. ${ }^{23,24}$ PCA with varimax rotation was conducted for a five-factor solution. 
Table 3. Item Characteristics of the 24-item Person Engagement Index Scale $(N=100)$

\begin{tabular}{|c|c|c|c|c|}
\hline Item & Mean (SD) & $\begin{array}{c}\text { Median } \\
(\mathrm{IQR})\end{array}$ & $\begin{array}{l}\% \text { of Min } \\
\text { Scores }(1-2)\end{array}$ & $\begin{array}{l}\% \text { of Max } \\
\text { Scores }(4-5)\end{array}$ \\
\hline 1. I am motivated to take charge of my healthcare. & $4.36(0.78)$ & $4(1)$ & 3.0 & 93.0 \\
\hline $\begin{array}{l}\text { 2. I have all the information I need to make an informed } \\
\text { decision about my healthcare. }\end{array}$ & $4.05(0.83)$ & $4(1)$ & 8.0 & 87.0 \\
\hline $\begin{array}{l}\text { 3. My healthcare goals are based on what is most important to } \\
\text { me. }\end{array}$ & $4.38(0.62)$ & $4(1)$ & 1.0 & 45.0 \\
\hline $\begin{array}{l}\text { 4. I have people in my life that I know I can rely on if I need } \\
\text { help taking care of my health. }\end{array}$ & $4.28(0.85)$ & $4(1)$ & 7.0 & 91.0 \\
\hline $\begin{array}{l}\text { 5. When something seems "not right" to me in my healthcare, } \\
\text { I speak up to my doctor, nurse, care team members or } \\
\text { family. }\end{array}$ & $4.39(0.76)$ & $5(1)$ & 5.0 & 93.0 \\
\hline $\begin{array}{l}\text { 6. I think that technology (i.e., computers, cellphones, email, } \\
\text { texting, video chat, etc.) either has or could be a good tool } \\
\text { to help better manage my health. }\end{array}$ & $3.86(1.04)$ & $4(1)$ & 17.0 & 69.0 \\
\hline 7. I take actions to make sure I am the healthiest I can be. & $4.15(0.80)$ & $4(1)$ & 13.0 & 87.0 \\
\hline $\begin{array}{l}\text { 8. I rely heavily on others to assist me with my health } \\
\text { problems. }\end{array}$ & $3.94(0.98)$ & $4(1)$ & 14.0 & 81.0 \\
\hline 9. My health is a priority in my life & $4.20(0.85)$ & $4(1)$ & 7.0 & 86.0 \\
\hline $\begin{array}{l}\text { 10. I understand what my healthcare choices are after speaking } \\
\text { with my doctor, nurse or care team members. }\end{array}$ & $4.27(0.65)$ & $4(1)$ & 3.0 & 95.0 \\
\hline $\begin{array}{l}\text { 11. I discuss my healthcare goals with my doctor, nurse or other } \\
\text { members of my care team. }\end{array}$ & $4.12(0.79)$ & $4(1)$ & 7.0 & 88.0 \\
\hline $\begin{array}{l}\text { 12. I am able to access healthcare for prevention and illness } \\
\text { when I need it. }\end{array}$ & $4.37(0.60)$ & $4(1)$ & 2.0 & 98.0 \\
\hline $\begin{array}{l}\text { 13. When I am concerned about my care, I tell my doctor, nurse } \\
\text { or care team members or family about the concern I have. }\end{array}$ & $4.34(0.59)$ & $4(1)$ & 1.0 & 96.0 \\
\hline $\begin{array}{l}\text { 14. I am open to receiving some of my healthcare through } \\
\text { technology (i.e., computers, cellphones, email, texting, video } \\
\text { chat, etc.). }\end{array}$ & $3.66(1.16)$ & $4(1)$ & 22.0 & 69.0 \\
\hline $\begin{array}{l}\text { 15. If I have a concern about my health, I take action to address } \\
\text { it. }\end{array}$ & $4.31(0.65)$ & $4(1)$ & 3.0 & 96.0 \\
\hline $\begin{array}{l}\text { 16. I have limited ability to participate in managing my health, } \\
\text { due to my health problems. }\end{array}$ & 3.93 (1.11) & $4(1)$ & 16.0 & 82.0 \\
\hline $\begin{array}{l}\text { 17. When I have a health concern, I want to learn more about it. } \\
\text { 18. I can tell others what is going on with my health. }\end{array}$ & $\begin{array}{l}4.36(0.58) \\
4.26(0.60)\end{array}$ & $\begin{array}{l}4(1) \\
4(1)\end{array}$ & 1.0 & $\begin{array}{l}97.0 \\
94.0\end{array}$ \\
\hline $\begin{array}{l}\text { 19. I see myself as part of my healthcare team that establishes } \\
\text { goals that matter to me. }\end{array}$ & $4.38(0.55)$ & $4(1)$ & 1.0 & 98.0 \\
\hline $\begin{array}{l}\text { 20. I have the necessary support from friends and family in my } \\
\text { life to achieve my health goals. }\end{array}$ & $4.10(0.79)$ & $4(1)$ & 7.0 & 89.0 \\
\hline $\begin{array}{l}\text { 21. I tell my doctors, nurses, care team or family members when } \\
\text { my healthcare may not be what I think I need. }\end{array}$ & $4.18(0.77)$ & $4(1)$ & 6.0 & 90.0 \\
\hline $\begin{array}{l}\text { 22. I have the capability to use technology (i.e., computers, } \\
\text { cellphones, email, texting, video chat, etc.) to assist me with } \\
\text { my healthcare. }\end{array}$ & $3.55(1.15)$ & $4(1)$ & 24.0 & 68.0 \\
\hline 23. I engage in activities to maintain my health. & $4.02(0.89)$ & $4(1)$ & 11.0 & 83.0 \\
\hline $\begin{array}{l}\text { 24. It is a challenge to participate in activities that would } \\
\text { improve my health, due to my health problems. }\end{array}$ & $3.18(1.24)$ & $4(2)$ & 37.0 & 52.0 \\
\hline
\end{tabular}

PCA with promax rotation to compare interpretability of the solution was conducted and did not improve the solution interpretability. Thus, varimax rotation was retained for the analysis.
After varimax rotation, the first component accounted for $32.5 \%$ of the total variance; the second component, $10.1 \%$; the third component $7.3 \%$; fourth component, $6.1 \%$; and the fifth component, $5.7 \%$. The five factors accounted for $61.7 \%$ of the total variance. The first 
Table 4. Internal Consistency and Factor Correlations of the Person Engagement Index Subscales $(N=100)$

\begin{tabular}{|c|c|c|c|c|c|c|c|}
\hline \multirow[t]{2}{*}{ Factors subscales } & \multirow{2}{*}{$\begin{array}{l}\text { Cronba- } \\
\text { ch's } \\
\text { alpha }\end{array}$} & \multirow[b]{2}{*}{ Mean (SD) } & \multirow{2}{*}{$\begin{array}{c}\text { Median } \\
\text { (Range, IQR) }\end{array}$} & \multicolumn{4}{|c|}{ Factor } \\
\hline & & & & I & II & III & IV \\
\hline Factor I: Knowledge of Healthcare status & 0.886 & $\begin{array}{c}82.13 \\
(12.08)\end{array}$ & $\begin{array}{c}78.13(50.00-100 \\
18.75)\end{array}$ & & & & \\
\hline $\begin{array}{l}\text { Factor II: Proactive Approach to } \\
\text { Healthcare }\end{array}$ & 0.780 & $\begin{array}{c}82.06 \\
(13.98)\end{array}$ & $\begin{array}{c}81.25(25.00-100 \\
18.75)\end{array}$ & .658 & & & \\
\hline $\begin{array}{l}\text { Factor III: Motivation to Manage } \\
\text { Healthcare }\end{array}$ & 0.742 & $\begin{array}{c}79.50 \\
(15.64)\end{array}$ & $\begin{array}{c}81.25(25.00-100 \\
25.00)\end{array}$ & .482 & .450 & & \\
\hline $\begin{array}{l}\text { Factor IV: Psychosocial Support for } \\
\text { Healthcare }\end{array}$ & 0.658 & $\begin{array}{c}72.30 \\
(16.38)\end{array}$ & $\begin{array}{l}75.00(20.00-100 \\
20.00)\end{array}$ & .272 & .249 & .266 & \\
\hline Factor V: Technology Use in Healthcare & 0.796 & $\begin{array}{c}65.83 \\
(23.59)\end{array}$ & $75.00(8.33-100,33.33)$ & .362 & .372 & .360 & .371 \\
\hline
\end{tabular}

Note. IQR Interquartile range; Higher numbers indicates higher capacity to engage.

Subscale means based on normalized subscale scores

component included eight of the 24 items, the second and third components each had four items, the fourth component had five items and the final component had three items. All loadings met the threshold of .40, ranging from .432 to .838 . Two items had similar magnitude loadings on two components: I engage in activities to maintain my bealth, .470 and .432 (component 3 and component 4, respectively), and When I am concerned about my care, I tell my doctor, nurse or care team members or family about the concern, .554 and .526 (component 1 and 2, respectively). Since the difference in the loadings on each factor was greater than .20 , the item was assigned to the factor with the higher loading. The first factor was labeled Knowledge of Healthcare Status, the second factor was labeled Proactive Approach to Healthcare, the third factor was labeled Motivation to Manage Healthcare, the fourth factor was labeled Psychosocial Support for Healthcare and the fifth factor was labeled Technology Use in Healthcare (Refer to Table 5 for item varimax rotated factor loading principle component analysis).

\section{Discussion}

The initial Person Engagement Index proposed eight domains. However, after exploratory factor analysis, five factors were extracted to explain the construct of a person's capacity to engage in their healthcare: Factor I (Knowledge of Healthcare Status), Factor II (Proactive Approach to Healthcare), Factor III (Motivation to Manage Healthcare), Factor IV (Psychosocial Support for Healthcare) and Factor V (Technology Use in Healthcare).

Results suggest that the Person Engagement Index is a valid and reliable instrument to measure the capacity to engage in healthcare among community-dwelling older adults. However, the Psychosocial Support domain's reliability, Cronbach's alpha $=.658$, was less than the .70 threshold, which contains the three items discussed that would improve the scale's reliability, along with two other items. With elimination of these three items, Cronbach's alpha of the Psychosocial Support domain would increase to .736.

Further testing is needed without these three items, which were part of the original disease burden domain.

This pilot study contributes to the research that supports the importance in considering a person's capacity to engage in their healthcare. Results of this pilot study are promising, however, further investigation is needed in a larger sample to test for reliable use in practice. Potential implications for use of the Person Engagement Index are discussed. Knowing a person's capacity to engage in their healthcare has the potential to assist with targeting areas of support needed to help people be better engaged in their care. This instrument was designed with the intent to be used among different populations to evaluate a person's capacity to engage in care at each encounter with the healthcare system, as well as ongoing evaluation of selfcare management. This was an exploratory pilot study to test the items among older community dwelling adults; further testing among various populations and settings is warranted. Future evaluation will determine if the use of the Person Engagement Index can help guide timely interventions that can potentially be implemented to assist people with self-care management. In addition, use of the instrument in education among interprofessional clinicians has the potential ability to help guide the direction of the care process, as well as engage people at the onset of their care to include them as partners in the plan based on their assessment.

\section{Limitations}

Limitations of this study include the sample size. Although exploratory in nature and meeting sampling adequacy criteria for this pilot study, these results should be 
Table 5. Varimax Rotated Factor Loadings, Principal Component Analysis of the Person Engagement Index Scale Items $(\mathrm{N}=100)$

\begin{tabular}{|c|c|c|c|c|c|}
\hline & Factor & & & & \\
\hline Item & I & II & III & IV & $\mathbf{V}$ \\
\hline I can tell others what is going on with my health. & .760 & & & & \\
\hline When I have a health concern, I want to learn more about it. & .731 & & & & \\
\hline $\begin{array}{l}\text { I see myself as part of my healthcare team that establishes goals that matter } \\
\text { to me. }\end{array}$ & .722 & & & & \\
\hline I am able to access healthcare for prevention and illness when I need it. & .691 & & & & \\
\hline $\begin{array}{l}\text { I tell my doctors, nurses, care team or family members when my healthcare } \\
\text { may not be what I think I need. }\end{array}$ & .672 & & & & \\
\hline $\begin{array}{l}\text { I understand what my healthcare choices are after speaking with my doctor, } \\
\text { nurse or care team members. }\end{array}$ & .664 & & & & \\
\hline $\begin{array}{l}\text { I discuss my healthcare goals with my doctor, nurse or other members of } \\
\text { my care team. }\end{array}$ & .633 & & & & \\
\hline $\begin{array}{l}\text { When I am concerned about my care, I tell my doctor, nurse or care team } \\
\text { members or family about the concern I have. }\end{array}$ & .554 & & & & \\
\hline $\begin{array}{l}\text { I have all the information I need to make an informed decision about my } \\
\text { healthcare. }\end{array}$ & & .743 & & & \\
\hline $\begin{array}{l}\text { When something seems "not right" to me in my healthcare, I speak up to } \\
\text { my doctor, nurse, care team members or family. }\end{array}$ & & .694 & & & \\
\hline If I have a concern about my health, I take action to address it. & & .689 & & & \\
\hline My healthcare goals are based on what is most important to me. & & .487 & & & \\
\hline I take actions to make sure I am the healthiest I can be. & & & .820 & & \\
\hline My health is a priority in my life & & & .742 & & \\
\hline I am motivated to take charge of my healthcare. & & & .725 & & \\
\hline I engage in activities to maintain my health. & & & .470 & & \\
\hline $\begin{array}{l}\text { I have limited ability to participate in managing my health, due to my health } \\
\text { problems. }\end{array}$ & & & & .838 & \\
\hline $\begin{array}{l}\text { It is a challenge to participate in activities that would improve my health, } \\
\text { due to my health problems. }\end{array}$ & & & & .695 & \\
\hline I rely heavily on others to assist me with my health problems. & & & & .519 & \\
\hline $\begin{array}{l}\text { I have the necessary support from friends and family in my life to achieve } \\
\text { my health goals. }\end{array}$ & & & & .501 & \\
\hline $\begin{array}{l}\text { I have people in my life that I know I can rely on if I need help taking care } \\
\text { of my health. }\end{array}$ & & & & .476 & \\
\hline $\begin{array}{l}\text { I am open to receiving some of my healthcare through technology (i.e., } \\
\text { computers, cellphones, email, texting, video chat, etc.). }\end{array}$ & & & & & .837 \\
\hline $\begin{array}{l}\text { I think that technology (i.e., computers, cellphones, email, texting, video } \\
\text { chat, etc.) either has or could be a good tool to help better manage my } \\
\text { health. }\end{array}$ & & & & & .803 \\
\hline $\begin{array}{l}\text { I have the capability to use technology (i.e., computers, cellphones, email, } \\
\text { texting, video chat, etc.) to assist me with my healthcare. }\end{array}$ & & & & & .675 \\
\hline Percent of Variance $($ Total $=61.7 \%)$ & 32.5 & 10.1 & 7.3 & 6.1 & 5.7 \\
\hline Cumulative Percent of Variance & 32.5 & 42.6 & 49.9 & 56.0 & 61.7 \\
\hline Cronbach's alpha $=.882$ (overall scale) & .886 & .780 & .742 & .658 & .796 \\
\hline
\end{tabular}

interpreted with caution due to the sample size of 100 . Nunnally recommends 10 cases per item for testing an instrument to measure the underlying construct; in this case, a sample of 240 is recommended. ${ }^{25}$ This pilot study included community-dwelling older adults only, limiting the generalizability of the results to other populations. Due to the construct being measured, testing in different settings and among other populations is warranted to account for health status changes that may impact a person's capacity to engage in their healthcare. Furthermore, social desirability response bias could be a factor in the results due to the construct being measured and the fact that questionnaire was delivered orally over the phone. 


\section{Conclusion}

Further testing of the Person Engagement Index is suggested to determine if the reduction in items, tested among various populations, in and out of various healthcare and community settings, results in acceptable psychometric properties to measure the construct of a person's capacity to engage in their healthcare. In addition, although this exploratory pilot study results are encouraging, the testing of the use of the instrument in practice in larger studies is needed. As patient engagement efforts continue to evolve and care delivery models emerge to create a true clinician and patient partnership for care, the Person Engagement Index has the potential to be used as an assessment instrument with the intent to help better engage people in healthcare based on their assessment results. It is hypothesized that knowing a person's capacity to be engaged in their healthcare and tailoring interventions, resources and support accordingly, can potentially assist with developing practical strategies to improve the patient experience across the care continuum and enhance selfcare management.

\section{References}

1. Agency for Healthcare Research and Quality [AHRQ]. http://www.ahrq.gov (2014). Accessed 3 Feb 2016.

2. Hibbard JH, Greene J. What the evidence shows about patient activation: Better health outcomes and care experiences; fewer data on costs. Health Aff. 2013;32(2):207-213.

3. Roseman D, Osborne-Stafsnes J, Amy CH, Boslaugh S, Slate-Miller K. Early lessons from four 'aligning forces for quality' communities bolster the case for patient-centered care. Health Aff. 2013;32(2):232-238.

4. Elwyn G, Barr PJ, Grande SW, Thompson R, Walsh T, Ozanne EM. Developing CollaboRATE: A fast and frugal patient-reported measure of shared decision making in clinical encounters. Patient Educ Couns. 2013;93(1):102-107.

5. Sofaer S, Schumann MJ. Fostering successful patient and family engagement: Nursing's critical role. Washington, DC: National Alliance for Quality Care. 2013. http://www.naqc.org/WhitePaperPatientEngagement. Accessed 3 Feb 2016.

6. Hibbard J, Stockard J, Mahoney E, Tusler M. Development of the Patient Activation Measure (PAM): Conceptualizing and measuring activation in patients and consumers. Health Serv Res. 2004;39(4):1005-1026.

7. Bauer UE, Briss PA, Goodman RA, Bowman BA. Prevention of chronic disease in the 21 st century: Elimination of the leading preventable causes of premature death and disability in the USA. The Lancet. 2014;384(9937):45-52.
8. IOM. (Institute of Medicine). 2008. Retooling for an aging America: Building the health care workforce. Washington, DC: The National Academies Press.

9. Drenkard K, Swartwout E, Deyo,P, O’Neil, M. Interactive Care Model: A framework for more fully engaging people in their healthcare. JON $A$. 2015;45(10):503-510.

10. Aruffo S. Can technology drive sustainable patient engagement? http:/ / www.dorlandhealth.com/dorland-healtharticles/CIP_0213_17_Teach Toolsxml 2014. Accessed16 Apr 2014..

11. Center for Advancing Health. A new definition of patient engagement: What is engagement and why is it important? Washington, DC. 2010. http //www.cfah.org/file /CFAH_Engagement_Behavior_Framework_current. pdf Accessed 16 Apr 2014.

12. Coulter A. Patient engagement: What works? I Ambul Care Manage. 2012;35(2):80-89.

13. Kowal J, Wilson KG, McWilliams LA, Peloquin K, Duong D. Self-perceived burden in chronic pain: Relevance, prevalence, and predictors. Pain. 2011;153(8):1735-1741.

14. Wolever RQ, Webber DM, Meunier JP, Greeson JM, Lausier ER, Gaudet TW. Modifiable disease risk, readiness to change, and psychosocial functioning improve with integrative medicine immersion model. Alt Ther Health Med. 2011;17(4):38-47.

15. Brazier JE, Harper R, Jones NMB, O'Cathain A, Thomas KJ, Usherwood T, Westlake L. Validating the SF-36 health survey questionnaire: New outcome measure for primary care. BMJ. 1992;305(6846):160164.

16. Center for Disease Control [CDC]. Behavioral Risk Factor Surveillance System (BRFSS). http://www.cdc.gov/brfss/ 2015. Accessed 3 Feb 2016.

17. Zimet GD, Dahlem NW, Zimet SG, Farley GK. (1988). The multidimensional scale of perceived social support. J Pers Assess. 1988;52(1):30-41.

18. Gilson BS, Gilson JS, Bergner M, Bobbitt RA, Kressel S, Pollard WE, Vesselago M. The sickness impact profile: Development of an outcome measure of healthcare. Am J Public Health. 1975;65(12):1304-1310.

19. Holden R, Karsh B. The technology acceptance model: Its past and its future in healthcare. J Biomed Inform. 2010;43(1):159-172.

20. Jordan J, Buchbinder R, Briggs A, Elsworth G, Busija L, Batterham R, Osborne RH. The health literacy management scale (HeLMS): A measure of an individual's capacity to seek, understand, and use health information within the healthcare setting. Patient Educ Couns. 2013;91(2):228-235.

21. Wallston KA, Cawthon C, McNaughton CD, Rothman R, Osborn CY, Kripalani S. Psychometric 
properties of the brief health literacy screen in clinical practice. J Gen Intern Med. 2014;29(1):119-126.

22. Polit DF, Tatano-Beck C. Ninth Edition. Nursing research: Generating and assessing evidence for nursing practice, $9^{\text {th }}$ Ed. Philadelphia: Lippincott Williams \& Wilkins; 2012.

23. Pett MA, Lackey NR, Sullivan JJ. Making sense of factor analysis: The use of factor analysis for instrument development in healthcare research. London: Sage; 2003.

24. Polit, DF. Statistics and data analysis for nursing research. $2^{\text {nd }}$ Ed. Upper Saddle River, NJ: Pearson; 2010.

25. Nunnally, JC. Second Edition. Pyschometric Theory., $2^{\text {nd }}$ Ed. New York: McGraw-Hill Publishing Company; 1978. 